\title{
Performance of hybrid systems coupling advanced oxidation processes and ultrafiltration for oxytetracycline removal
}

\author{
Jonathan C. Espíndola ${ }^{\mathrm{a}, \mathrm{c}}$, Kacper Szymański ${ }^{\mathrm{b}}$, Raquel O. Cristóvão ${ }^{\mathrm{a}}$, Adélio Mendes ${ }^{\mathrm{d}}$, \\ Vítor J.P. Vilar ${ }^{\mathrm{a}, *}$, Sylwia Mozia ${ }^{\mathrm{b}, *}$ \\ a Laboratory of Separation and Reaction Engineering-Laboratory of Catalysis and Materials (LSRE-LCM), Department of Chemical Engineering, Faculty of Engineering, \\ University of Porto, Rua do Dr. Roberto Frias, 4200-465, Porto, Portugal \\ ${ }^{\mathrm{b}}$ West Pomeranian University of Technology, Szczecin, Faculty of Chemical Technology and Engineering, Institute of Inorganic Technology and Environment Engineering, \\ Pułaskiego 10, 70-322, Szczecin, Poland \\ ${ }^{\mathrm{c}} \mathrm{CNPq}$ - National Council for Scientific and Technological Development, Brazil \\ ${ }^{\mathrm{d}}$ LEPABE - Laboratory for Process, Environment, Biotechnology and Energy Engineering, Faculdade de Engenharia, Universidade Do Porto, Rua Dr. Roberto Frias, 4200- \\ 465, Porto, Portugal
}

\section{A R T I C L E I N F O}

\section{Keywords:}

Hybrid system

Photocatalytic membrane reactor

$\mathrm{UVC} / \mathrm{H}_{2} \mathrm{O}_{2}$ process

Membrane fouling

Oxytetracycline

\begin{abstract}
A B S T R A C T
In this study, the efficiency of three different hybrid systems coupling ultrafiltration (UF) with (i) $\mathrm{UVC} / \mathrm{H}_{2} \mathrm{O}_{2}$, (ii) $\mathrm{UVC} / \mathrm{TiO}_{2}$, and (iii) UVC was evaluated for the treatment of a secondary effluent (SE) from a municipal wastewater treatment plant and a surface water (SW) from Miedwie Lake, both spiked with $5 \mathrm{mg} \mathrm{L}^{-1}$ of oxytetracycline (OTC). A ceramic membrane made of $\mathrm{TiO}_{2}$ was tested. The effect of $\mathrm{H}_{2} \mathrm{O}_{2}$ concentration (30 to $\left.120 \mathrm{mg} \mathrm{L}^{-1}\right)$ on the $\mathrm{UVC} / \mathrm{H}_{2} \mathrm{O}_{2}$-UF system and of $\mathrm{P} 25-\mathrm{TiO}_{2}$ loading $\left(0.5\right.$ to $\left.1.5 \mathrm{~g} \mathrm{~L}^{-1}\right)$ in suspension on the photocatalytic $\mathrm{UVC} / \mathrm{TiO}_{2}$-UF system were investigated. A photonic flux of $5.1 \mathrm{~J} \mathrm{~s}^{-1}$ was provided in all systems. The maximum pure water flux (PWF) was $111 \mathrm{~L} \mathrm{~m}^{-2} \mathrm{~h}^{-1}$. Adsorption on the photocatalyst particles and/or on the membrane surface was found to be an important contribution for the removal of OTC and dissolved organic carbon (DOC). The UF membrane contributed significantly to photocatalyst and pollutants rejection in the photocatalytic membrane reactor (PMR) with the $\mathrm{UVC} / \mathrm{TiO}_{2}$ system; whereas when using the $\mathrm{UVC} / \mathrm{H}_{2} \mathrm{O}_{2} \mathrm{pro}-$ cess, with the highest $\mathrm{H}_{2} \mathrm{O}_{2}$ dose, the membrane effect was negligible. Using SE as reaction matrix in the UVC/ $\mathrm{TiO}_{2}$-UF system with $1.0 \mathrm{~g} \mathrm{~L}^{-1}$ of $\mathrm{TiO}_{2}$, the complete OTC removal was achieved in $5 \mathrm{~h}$ with a mineralization of $49 \%$. For the same reaction period, a DOC removal of $52 \%$ was achieved with the UVC $/ \mathrm{H}_{2} \mathrm{O}_{2}$-UF system (120 mg $\mathrm{H}_{2} \mathrm{O}_{2} \mathrm{~L}^{-1}$ ). A similar permeate flux decrease ( $c$. 40\%) was observed in both cases. Furthermore, the highest reduction of permeate flux $(60 \%)$ was observed when using the UVC-UF system. Using SW as reaction matrix, higher OTC degradation rates and percentage of mineralization were reached for the same reaction period, when compared with SE, due to the lower COD and inorganic salts concentration present in the surface water.
\end{abstract}

\section{Introduction}

Antibiotics are a special group of pharmaceuticals used to treat bacterial infections in human and veterinary medicine [1]. Commonly, these compounds are not completely metabolized and are excreted as active substances [2]. The conventional treatments used in urban wastewater treatment plants (WWTPs) are not efficient to completely remove those contaminants of emerging concern (CECs), leading to their release into the aquatic systems, causing adverse effects on surroundings [3]. Several studies have reported the occurrence of antibiotics in the aquatic environments [4-6]. Therefore, robust new methods must be implemented to safely discharge those effluents into the environment.

Advanced oxidation processes (AOPs) have been successfully applied for the removal of antibiotics from aqueous solutions [7]. Among AOPs, the ultraviolet $\mathrm{C}$ light (UVC) combined with hydrogen peroxide (UVC/ $\mathrm{H}_{2} \mathrm{O}_{2}$ system) is widely used due to its high efficiency in hydroxyl radicals production. Regarding photocatalysis, crystalline titanium dioxide (Evonik P25- $\mathrm{TiO}_{2}$ ), with a unique combination of anatase (predominantly) and rutile crystal structures, has effectively become a standard as photocatalyst [8]. Hybrid systems coupling the AOPs advantages with membrane technologies have gained significant attention in recent years for the treatment of aqueous solutions [9]. Photocatalytic membrane reactors (PMRs) can be divided into two main

\footnotetext{
* Corresponding authors.

E-mail addresses: vilar@fe.up.pt (V.J.P. Vilar), sylwia.mozia@zut.edu.pl (S. Mozia).
} 
groups: (i) systems with a photocatalyst suspended in the reaction solution and (ii) systems with the photocatalyst immobilized in or on the surface of the membrane (photocatalytic membranes). In the first case, the photocatalyst active surface area is much larger than in the second one and the membrane plays the important role of selective barrier for the photocatalyst particles, allowing their reuse $[10,11]$. In addition, it could serve also as barrier for the compounds to be degraded. In the latter system, the membrane functionalization with photocatalyst improves the membrane performance, through in-situ degradation of pollutants, enhancing the antifouling properties of the membranes and achieving a high quality permeate [11].

The most described PMRs focuses mainly on systems utilizing polymeric membranes with a photocatalyst in suspension. However, the application of this type of membranes in PMRs has some serious drawbacks due to their low resistance to UV light and their possible destruction by hydroxyl radicals [12-14]. On the other hand, inorganic membranes, especially ceramic membranes, are more stable and resistant to chemical factors and UV radiation. Furthermore, ceramic membranes exhibit other advantages that make them more appropriate for PMRs applications: high/low pH stability, high temperature tolerance and pressure resistance, long service life and abrasion resistance [15]. The main ceramic membrane materials used are $\mathrm{Al}_{2} \mathrm{O}_{3}, \mathrm{ZrO}_{2}$ or $\mathrm{TiO}_{2}$. Above all, pure titanium dioxide membranes exhibit major advantages, due to their highly hydrophilic surface and, as a consequence, good fouling resistance properties [16].

Besides pollutants degradation, sorption effects have been reported during the treatment of pharmaceuticals by PMRs on the membrane and/or on the $\mathrm{TiO}_{2}$ surface. With respect to the adsorption on the photocatalyst particles, its isoelectric point (point of zero charge, PZC) determines the adsorption efficiency of the compounds. For the commonly used Evonik $\mathrm{P} 25-\mathrm{TiO}_{2}$ the $\mathrm{pH}_{\mathrm{PZC}}$ is 6.8 [17]. At higher $\mathrm{pH}$ values, the $\mathrm{TiO}_{2}$ particles tend to adsorb positively charged contaminants; while for lower $\mathrm{pH}$ values, the adsorption of negatively charged pollutants is favored. The adsorption of organic compounds on the membrane revealed also to be an important removal process, which usually occurs at the initial stage of the filtration being influenced by the membrane surface, the support layer and the membrane pores [18-20].

Oxytetracycline (OTC) is an important broad spectrum antibiotic widely used in veterinary medicine to control infectious diseases and growth promotion [21]. Its use has been described in different animal productions, such as livestock [22,23] and aquaculture [23,24]. Most OTC is excreted without being metabolized, leading to its frequent detection in the environment [21]. OTC concentrations in the range from 0.23 to $0.71 \mathrm{mg} \mathrm{L}^{-1}$ have been reported in surface waters in China [25], while dosages up to $0.34 \mu \mathrm{g} \mathrm{L}^{-1}$ have been detected in rivers in the United States [26]. In the vicinity of animal production in Iowa, OTC was also detected in groundwater samples [23]. Although studies on the OTC removal by UVC $/ \mathrm{H}_{2} \mathrm{O}_{2}$ process [27], photo-Fenton [28], anodic oxidation [29], UV-254 nm/activated persulfate (PS) [30], $\mathrm{TiO}_{2}$ photocatalysis [31] and membrane separation [32] have been reported in the literature, to the best of our knowledge, none using AOPs-UF hybrid systems with different effluent matrices has been described.

The main aim of the present work was to assess the degradation of a model antibiotic, OTC, using three different hybrid processes: UVC/ $\mathrm{TiO}_{2}$ photocatalysis (with $\mathrm{TiO}_{2}$ in suspension), UVC photolysis and UVC $/ \mathrm{H}_{2} \mathrm{O}_{2}$ oxidation combined with UF using a ceramic membrane. The matrix effect was evaluated by spiking OTC in a secondary effluent from a municipal wastewater treatment plant (MWWTP) and in surface water from Miedwie Lake, Poland.

\section{Materials and methods}

\subsection{Wastewater and surface water}

A real wastewater sample was collected downstream the secondary treatment of a sewage treatment plant from Northwest Poland. The natural surface water was obtained from Miedwie Lake, a main drinking water supply for Szczecin, Poland. The respective water quality parameters are summarized in Table S1 in the supplementary material. It is possible to observe that the secondary effluent (SE) is a more complex matrix than the surface water (SW), presenting higher values of all the parameters analyzed, such as organic matter, dissolved solids and inorganic ions. Feed solutions used in the experiments were prepared using these waters spiked with OTC $\left([\mathrm{OTC}]_{0}=5 \mathrm{mg} \mathrm{L}^{-1}\right)$.

\subsection{Chemicals}

Oxytetracycline hydrochloride (OTC, $\mathrm{C}_{22} \mathrm{H}_{24} \mathrm{~N}_{2} \mathrm{O}_{9} \cdot \mathrm{HCl}, 496.89 \mathrm{~g}$ / mol) was supplied by Sigma-Aldrich and used as a model compound. The initial concentration of OTC ([OTC $]_{0}$ ) was $5 \mathrm{mg} \mathrm{L}^{-1}$ which corresponded to $35 \mathrm{mg}$ of its mass in a feed solution. Titanium(IV) oxide $\left(\mathrm{TiO}_{2}\right)_{\text {) Aeroxide }}{ }^{\circledast} \mathrm{P} 25$ (Evonik, Germany; average particle size of $21 \mathrm{~nm}$, BET specific surface area of $35-65 \mathrm{~m}^{2} \mathrm{~g}^{-1}$, density of $4.26 \mathrm{~g} \mathrm{~cm}^{-3}, 80 \%$ wt. anatase and $20 \% \mathrm{wt}$. rutile crystalline phases) $\geq 99.5 \%(\mathrm{w} / \mathrm{w})$ purity was used as suspended photocatalyst in concentrations of 0.5 , 1.0 or $1.5 \mathrm{~g} \mathrm{~L}^{-1}$. The hydrogen peroxide supplied by Avantor Performance Materials Poland S.A. was used in UVC $/ \mathrm{H}_{2} \mathrm{O}_{2}$ experiments $\left(30<\left[\mathrm{H}_{2} \mathrm{O}_{2}\right]_{0}<120 \mathrm{mg} \mathrm{L}^{-1}\right)$ and in photonic flux measurements. Ultrapure water (Simplicity ${ }^{\mathrm{Tm}}$, Millipore) was used for membrane cleaning and as matrix in some experiments. The acetonitrile and methanol used for HPLC analysis were obtained from Scharlau and oxalic acid dehydrate (100\%) by Merck Millipore.

A tubular asymmetric ceramic ultrafiltration membrane with molecular mass cut-off (MMCO, according to manufacturer) of $10 \mathrm{kDa}$ and brand name of "Filtanium" (TAMI Industries, France) was used in the experiments. This membrane is made of titanium dioxide, with $0.25 \mathrm{~m}$ of length and with external and internal diameters of 0.01 and $0.006 \mathrm{~m}$, respectively. The effective membrane area was $47 \times 10^{-4} \mathrm{~m}^{2}$. Before experiments, this brand new membrane was chemically cleaned with $\mathrm{NaOH}$ and $\mathrm{H}_{3} \mathrm{PO}_{4}$ solutions according to the procedure recommended by the manufacturer.

\subsection{Experimental procedure}

The studies were carried out in a lab-scale installation equipped with two flow-through photoreactors $\left(V_{\text {illuminated }}=0.84 \mathrm{~L}\right.$ each) containing one UVC lamp each (Philips TUV $16 \mathrm{~W}, \lambda_{\max }=254 \mathrm{~nm}$, photonic flux of $5.1 \pm 0.1 \mathrm{~J} \mathrm{~s}^{-1}$ ). The respective schematic representation was already presented by Szymański et al. [33] and can be seen in the supplementary material (Fig. S1). The photoreactors were installed between the feed tank and the membrane module made of stainless steel, with $0.25 \mathrm{~m}$ of length and $0.015 \mathrm{~m}$ of diameter, where the ceramic membrane was housed. The membrane was not irradiated by UV light, not acting photocatalytically in the reaction. The filtration was carried out in the inside-out mode. According to previous works of the group $[33,34]$, a feed cross-flow velocity (CFV) of $6 \mathrm{~m} \mathrm{~s}^{-1}$ and a transmembrane pressure (TMP) of $0.1 \mathrm{MPa}$ were selected, taking into account their influence on the membrane fouling. The permeate flux was estimated measuring the volume permeated through the membrane during a certain period of time. The maximum pure water flux (PWF) was $111 \mathrm{~L} \mathrm{~m}^{-2} \mathrm{~h}^{-1}$. The initial permeate flux $\left(J_{0}\right)$ was measured with ultrapure water at the beginning of each experiment, corresponding approximately to the PWF. The feed tank was filled with $7 \mathrm{~L}$ of OTC solution $\left(5 \mathrm{mg} \mathrm{L}^{-1}\right)$ and the temperature was set at $(20 \pm 1)^{\circ} \mathrm{C}$. Except for UF only and UVC photolysis systems, different $\mathrm{H}_{2} \mathrm{O}_{2}$ or photocatalyst amounts were initially added to the feed tank. Using the PMR with the $\mathrm{UVC} / \mathrm{TiO}_{2}$-UF system, before turning on the UVC lamps $(t$ $=0 \mathrm{~min}$ ), the OTC adsorption on the photocatalyst was evaluated during $30 \mathrm{~min}$ followed by $10 \mathrm{~min}$ of recirculation throughout the entire installation to evaluate OTC adsorption on the membrane (with the permeate valve closed). In the $\mathrm{UVC} / \mathrm{H}_{2} \mathrm{O}_{2}$-UF experiments (without photocatalyst), the OTC adsorption on the membrane surface was 
carried out in the dark during $10 \mathrm{~min}$, before oxidant addition, also with the permeate valve closed. The different dark periods to evaluate OTC adsorption by $\mathrm{TiO}_{2}$ particles or by the membrane were selected based on analysis of changes of OTC concentration. It was found that elongation of adsorption time above $30 \mathrm{~min}$ and $10 \mathrm{~min}$, respectively, did not contribute to significant changes of OTC concentration in the feed.

The amount of OTC adsorbed on $\mathrm{TiO}_{2}$ nanoparticles or on the UF membrane is calculated according to Eq. 1 (mass balance of a batch reactor).

$q_{t}=\frac{V}{m} \times\left([O T C]_{0}-[O T C]_{t}\right)$

where $q_{t}$ is the concentration of OTC in the solid phase at time $t$ (mg $\left.\mathrm{g}^{-1}\right),[\mathrm{OTC}]_{0}$ is the initial concentration of OTC in the liquid phase (mg $\left.\mathrm{L}^{-1}\right),[\mathrm{OTC}]_{\mathrm{t}}$ is the concentration of OTC in the liquid phase at time $t$ ( $\mathrm{mg} \mathrm{L}^{-1}$ ), $m$ is the $\mathrm{TiO}_{2}$ or the membrane mass $(\mathrm{g})$ and $V$ is the solution volume (L).

After checking the OTC adsorption by the $\mathrm{TiO}_{2}$ and/or the membrane in all systems, the UVC lamps were turned on, the permeate valve was opened and the experiments were conducted for $5 \mathrm{~h}$ with the recirculation of the permeate to the feed tank. The permeate flux $(J)$ and OTC/DOC removal efficiency were evaluated at different time intervals. The photonic flux was determined by $\mathrm{H}_{2} \mathrm{O}_{2}(73.5 \mathrm{mM})$ actinometry [quantum yield $(\Phi)=1.11$ ] [35].

\subsection{Analytical determinations}

The OTC concentration was determined by HPLC LaChrom Elite (Hitachi, Japan) equipped with UV/Vis detector. The reverse-phase column used was a Purospher ${ }^{\circledR}$ STAR RP-18 250-4 (5 $\left.\mu \mathrm{m}\right)$ (Merck). The detailed description of the analytic system and procedure can be consulted elsewhere [7]. Inorganic ions concentration were determined by ion chromatography (850 Professional IC, Herisau Metrohm, Switzerland). The analysis was performed according to the procedure already described by Mozia et al. [36]. The $\mathrm{H}_{2} \mathrm{O}_{2}$ concentration was measured by the colorimetric metavanadate method [37]. Dissolved organic carbon (DOC) and dissolved inorganic carbon (DIC) were monitored using a multi N/C 3100 analyzer (Analytik Jena, Germany). $\mathrm{Na}_{2} \mathrm{SO}_{3}$ in a $\mathrm{Na}_{2} \mathrm{SO}_{3}$-to- $\mathrm{H}_{2} \mathrm{O}_{2}$ molar ratio of 1:1 [38] was added to OTC and DOC samples to stop the degradation process. Chemical oxygen demand (COD) was measured by Merck ${ }^{\circledR}$ Spectroquant kit. Conductivity, total dissolved solids (TDS), $\mathrm{UV}_{254}$ absorbance, $\mathrm{pH}$ and turbidity were evaluated according to methods already described by Szymański et al. [39]. Before determination of OTC concentration, DOC, inorganic anions, $\mathrm{UV}_{254}$ absorbance, conductivity and TDS parameters, samples were filtered through $0.45 \mu \mathrm{m}$ Nylon filters from Cole-Parmer.

\section{Results and discussion}

\subsection{OTC removal from secondary effluent in the photocatalytic membrane reactor by $\mathrm{UVC} / \mathrm{TiO}_{2}$-UF hybrid system}

Initially, OTC adsorption on the $\mathrm{TiO}_{2}$ particles during the treatment of the SE spiked with $5 \mathrm{mg} \mathrm{L}^{-1}$ of OTC by the PMR with the UVC/TiO $2^{-}$ UF system was analyzed for $30 \mathrm{~min}$ before turning on the UVC lamps (without recirculation through the membrane module), until reach equilibrium. The increase on the $\mathrm{TiO}_{2}$ dosage from 0.5 to $1.5 \mathrm{~g} \mathrm{~L}^{-1}$ showed to enhance the OTC removal efficiency from 12 to $36 \%$, respectively. The $\mathrm{pH}$ of the feed solutions was around 7.4, value above the point of zero charge of $\mathrm{TiO}_{2}\left(\mathrm{pH}_{\mathrm{PZC}}=6.8\right.$ [17]). Under these conditions, the photocatalyst surface is negatively charged and the OTC species are almost evenly distributed between its zwitterion, $\mathrm{H}_{2} \mathrm{OTC}^{ \pm}$, and anionic HOTC- forms (according to OTC speciation diagram [7]). Therefore, the observed OTC adsorption is probably due to the interaction between the $\mathrm{TiO}_{2}$ photocatalyst particles and the zwitterion
$\mathrm{H}_{2} \mathrm{OTC}^{ \pm}$species. Pereira et al. [7] reported a significant OTC adsorption on $\mathrm{TiO}_{2}$ surface (35\%) when working with an OTC pure solution (20 $\mathrm{mg} \mathrm{L}^{-1}$ ) using $0.5 \mathrm{~g} \mathrm{TiO}_{2} \mathrm{~L}^{-1}$ at $\mathrm{pH}$ 7.5. In our study, using $\mathrm{SE}$ as solution matrix, OTC adsorption was almost 3 times lower (12\%) than that observed for the same $\mathrm{TiO}_{2}$ dosage $\left(0.5 \mathrm{~g} \mathrm{TiO}_{2} \mathrm{~L}^{-1}\right)$ using a pure solution of OTC (35\%). This is mainly related to the present of additional organic and inorganic species in the SE matrix, which affects negatively the OTC adsorption on the photocatalyst surface. It should be noted that, even with the SE as reaction matrix, a higher OTC adsorption (36\%) was observed when using a higher $\mathrm{TiO}_{2}$ concentration $\left(1.5 \mathrm{~g} \mathrm{TiO}_{2} \mathrm{~L}^{-1}\right)$, due to the greater availability of photocatalyst sorption sites. In this case, an amount of $1.1 \mathrm{mg}$ of OTC was adsorbed per gram of $\mathrm{TiO}_{2}$.

Subsequently, the OTC adsorption on the membrane was evaluated, before turning on the UVC lamps, by recirculating the feed solution through the entire installation for $10 \mathrm{~min}$ (with the permeate valve closed). At the end of this process, an additional decrease in the OTC concentration (in relation to the one obtained after the $\mathrm{TiO}_{2}$ particles addition) of about 13-29\% was observed. It should be noted that all the used tubing is made of stainless steel in order to avoid the adsorption of organic species. Therefore, it was ensured that the decrease to OTC concentration in the liquid phase during the dark period corresponds only to its adsorption on the $\mathrm{TiO}_{2}$ membrane. It is known that relatively low molecular weight organic compounds (OTC) can access and diffuse to the membrane's internal sites and pores [18], and may, subsequently, be desorbed into the permeate. In order to confirm this behavior, an adsorption experiment was performed where the membrane was immersed in a beaker with an OTC solution $\left([\mathrm{OTC}]_{0}=5 \mathrm{mg} \mathrm{L}^{-1}\right.$ ) until reach equilibrium $(24 \mathrm{~h})$. At the studied conditions, a reduction of $21 \%$ on the OTC concentration in the liquid phase was observed, corresponding to an adsorption capacity of $7.2 \times 10^{-3} \mathrm{mg}$ of OTC per gram of membrane. In order to verify the OTC sorption under process conditions, ultrafiltration alone (in the darkness) was analyzed. In case of SW the most significant decrease of OTC in feed was observed after $10 \mathrm{~min}$ (15\%) and did not change even after $2 \mathrm{~h}$. When SE was applied as a feed, the highest decrease (11\%) of OTC content caused by the sorption occurred after $10 \mathrm{~min}$ and during next $20 \mathrm{~min}$ of the process it reached $16 \%$. The observed difference between OTC adsorption in case of SE and SW can be attributed to the presence of suspended solids, which concentration in the wastewater was higher, as can be judged from turbidity values. The suspended solids played a role of adsorbent and therefore the final removal of OTC in SE was slightly higher compared to SW. On the opposite, a more complex composition of SE compared to SW resulted in a slightly slower adsorption due to competition between wastewater components and OTC.

Thereafter, the influence of $\mathrm{TiO}_{2}$ concentration on the permeate flux during the treatment of SE spiked with $5 \mathrm{mg} \mathrm{L}^{-1}$ of OTC in the PMR was evaluated (Fig. 1a, Table 1). When the experiment was performed with $\mathrm{TiO}_{2}$ suspended in distilled water spiked with OTC, no membrane fouling was observed in the system, and the permeate flux was equal to pure water flux (PWF) (data not shown). However, when studying the OTC removal from SE, the permeate flux declined over time indicating that contaminants present in the wastewater contributed to membrane fouling. Nonetheless, the permeate flux increased with photocatalyst loading increase from 0.5 to $1.0 \mathrm{~g} \mathrm{~L}^{-1}$. Table 1 presents a comparison between the OTC total degradation times (below the detection limit), permeate flux deterioration and DOC removals achieved after $5 \mathrm{~h}$ of treatment for both reaction matrices, SE and SW, with the different hybrid systems studied. When using $0.5 \mathrm{~g} \mathrm{TiO}_{2} \mathrm{~L}^{-1}$, at the end of the reaction, the permeate flux decreased for $50 \%$ and, in the case of $1.0 \mathrm{~g}$ $\mathrm{TiO}_{2} \mathrm{~L}^{-1}$, it was reduced $38 \%$. This difference may be due to the greater removal of organic contaminants with a higher photocatalyst amount. On the other hand, an increase in the $\mathrm{TiO}_{2}$ dosage to $1.5 \mathrm{~g} \mathrm{~L}^{-1}$ did not have significant improvements in the permeate flux. Despite allowing more active photocatalyst sites, a higher $\mathrm{TiO}_{2}$ amount can also hinder the light penetration, decreasing the degradation of the organic 


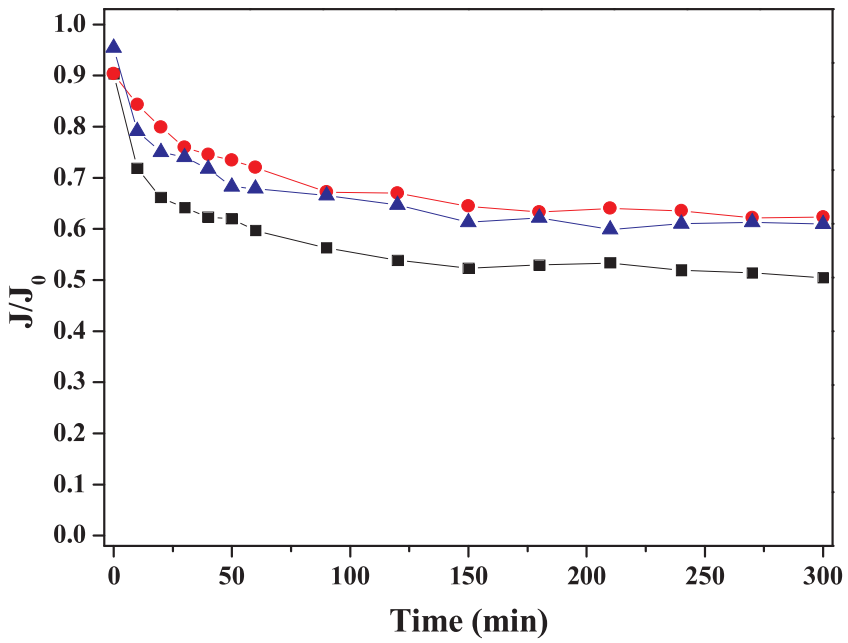

(a)

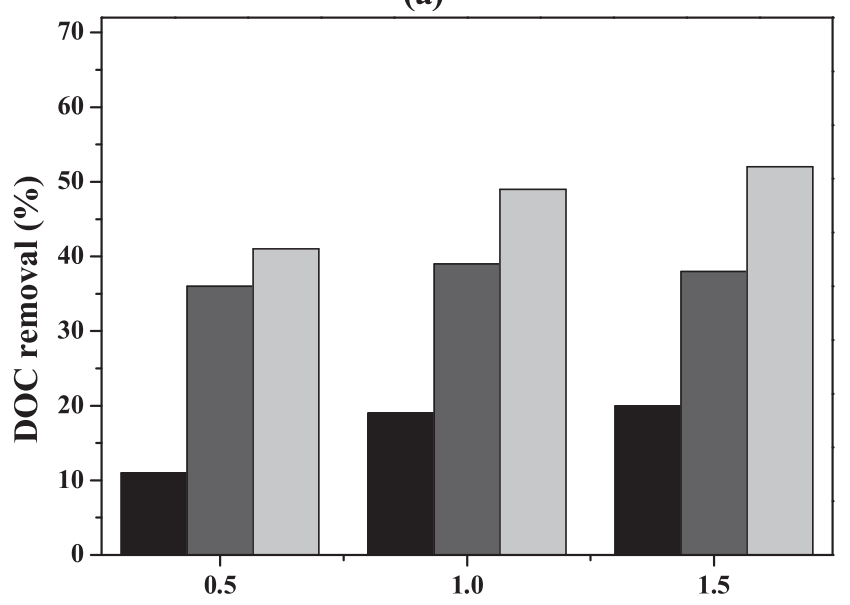

$\mathrm{TiO}_{2}$ concentration $\left(\mathrm{g} \mathrm{L}^{-1}\right)$

(b)

Fig. 1. Effect of $\mathrm{TiO}_{2}$ dosage on: a) permeate flux $\left[\mathrm{TiO}_{2}\right]$ : $(\square) 0.5$, ( $(\bigcirc) 1.0$ and (A) $1.5 \mathrm{~g} \mathrm{~L}^{-1}$; and b) DOC removal $(\square) \mathrm{R}_{\mathrm{ads}},(\square) \mathrm{R}_{\text {feed }}$ and $(\square) \mathrm{R}_{\text {total }}$ during OTC removal from a $\mathrm{SE}$ using the $\mathrm{UVC} / \mathrm{TiO}_{2}$-UF system. Conditions: $[\mathrm{OTC}]_{0}=5.0 \mathrm{mg} \mathrm{L}^{-1} ; \mathrm{pH}=7.4, \mathrm{~T}=20^{\circ} \mathrm{C} ; \mathrm{CFV}=6 \mathrm{~m} \mathrm{~s}^{-1} ; \mathrm{TMP}=0.1 \mathrm{MPa}$. compounds, increasing, consequently, the membrane fouling.

The total OTC degradation (below the detection limit $=0.01 \mathrm{mg} \mathrm{L}^{-1}$ ) was achieved after $20 \mathrm{~min}$ of reaction for all the $\mathrm{TiO}_{2}$ doses tested (Table 1). It is important to note that the adsorption/ desorption phenomenon of the OTC from the membrane was observed during all the experiments. For example, when using $1 \mathrm{~g} \mathrm{TiO}_{2} \mathrm{~L}^{-1}$ in the PMR set up, as the photocatalytic process plays an important role in the OTC removal from the concentrate, the antibiotic is no longer detected after $20 \mathrm{~min}$ (Fig. S2). On the other hand, the removal profile of OTC in the permeate presents a peculiar behavior. Initially, the membrane retains the pharmaceutical molecule, probably due to the initial adsorption effect. However, after $15 \mathrm{~min}$ it is possible to detect again the antibiotic in the reaction solution. Even when the compound was totally removed from the feed solution (after $20 \mathrm{~min}$ ), a concentration of $0.1 \mathrm{mg} \mathrm{L}^{-1}$ was detected in the permeate due to the continuous desorption of the molecule from the membrane. The maximum OTC concentration detected in the permeate was $0.4 \mathrm{mg} \mathrm{L}^{-1}$ (9\% of the initial value). Since the permeate is continuously recycled, the antibiotic molecules were totally photodegraded and no longer detected after 120 min. Regarding DOC, the values measured in the permeate (collected at sampling point SP2 in Fig. S1) were always lower than the ones measured in the feed (collected at sampling point SP1 in Fig. S1) at the same time. This indicates that larger molecular weight organic compounds present in the SE are rejected by the membrane.

In Fig. $1 \mathbf{b}$ it is presented, for the different $\mathrm{TiO}_{2}$ dosages, a comparison between: (i) the DOC removal efficiency due to the adsorption on the photocatalyst particles $\left(R_{\mathrm{ads}}=\left[F_{0}-F_{\mathrm{ads}}\right] / F_{0} \times 100 \%\right)$, (ii) the overall efficiency of DOC removal in the feed $\left(R_{\text {feed }}=\left[F_{0}-F_{5}\right] /\right.$ $F_{0} \times 100 \%$ ), and (iii) the total efficiency of DOC removal, regarding the feed and permeate composition $\left(R_{\text {total }}=\left[F_{0}-P_{5}\right] / F_{0} \times 100 \%\right) . F_{0}$ represents the feed initial DOC concentration, $F_{\text {ads }}$ is the feed DOC after adsorption, $F_{5}$ is the DOC concentration in the feed after $5 \mathrm{~h}$ of treatment and $P_{5}$ is the DOC concentration on the permeate after a reaction period of $5 \mathrm{~h}$. It can be observed that the adsorption of organic contaminants on the photocatalyst particles significantly influenced the treatment efficiency in the PMR. DOC removal due to adsorption increased from $11 \%$ to $20 \%$ when $\mathrm{TiO}_{2}$ concentration increased from 0.5 to $1.0 \mathrm{~g} \mathrm{~L}^{-1}$. A further increase on $\mathrm{TiO}_{2}$ amount had a negligible effect on DOC removal by adsorption. The total DOC removal observed using the $\mathrm{UVC} / \mathrm{TiO}_{2}$-UF system $\left(R_{\text {total }}\right)$ ranged from $41 \%$ to $52 \%$ and no significant improvement was observed for $\mathrm{TiO}_{2}$ concentrations higher than $1.0 \mathrm{~g} \mathrm{~L}^{-1}$. In this case, the photocatalyst particles probably start to contribute to the so-called screening effect: higher $\mathrm{TiO}_{2}$ dosages can

Table 1

Comparison of OTC total degradation times in the feed, DOC removals in the feed and permeate after $5 \mathrm{~h}$ of reaction and permeate flux deterioration when using SE and SW as reaction matrix with different hybrid systems.

\begin{tabular}{|c|c|c|c|c|c|}
\hline \multirow[t]{2}{*}{ Matrix } & \multirow[t]{2}{*}{ Hybrid system } & \multirow{2}{*}{$\begin{array}{l}\text { OTC } \\
\text { degradation time } \\
(\mathrm{min})\end{array}$} & \multicolumn{2}{|c|}{$\begin{array}{l}\text { DOC removal } \\
(\%)\end{array}$} & \multirow[t]{2}{*}{$\boldsymbol{J}_{5} / \boldsymbol{J}_{\mathrm{O}}^{\mathrm{b}}$} \\
\hline & & & Feed $^{\mathrm{c}}$ & Permeate $^{\mathrm{d}}$ & \\
\hline \multirow[t]{7}{*}{ SE } & UVC-UF & 90 & 22 & 30 & 0.40 \\
\hline & $\mathrm{UVC} / \mathrm{TiO}_{2}$-UF $\left(0.5 \mathrm{~g} \mathrm{TiO}_{2} \mathrm{~L}^{-1}\right)$ & 20 & 36 & 41 & 0.50 \\
\hline & $\mathrm{UVC} / \mathrm{TiO}_{2}$-UF $\left(1.0 \mathrm{~g} \mathrm{TiO}_{2} \mathrm{~L}^{-1}\right)$ & 20 & 39 & 49 & 0.62 \\
\hline & $\mathrm{UVC} / \mathrm{TiO}_{2}$-UF $\left(1.5 \mathrm{~g} \mathrm{TiO}_{2} \mathrm{~L}^{-1}\right)$ & 15 & 38 & 52 & 0.61 \\
\hline & $\mathrm{UVC} / \mathrm{H}_{2} \mathrm{O}_{2}$-UF $\left(30 \mathrm{mg} \mathrm{H} \mathrm{O}_{2} \mathrm{~L}^{-1}\right)$ & 30 & 35 & 41 & 0.48 \\
\hline & $\mathrm{UVC} / \mathrm{H}_{2} \mathrm{O}_{2}$-UF $\left(60 \mathrm{mg} \mathrm{H}_{2} \mathrm{O}_{2} \mathrm{~L}^{-1}\right)$ & 20 & 47 & 51 & 0.50 \\
\hline & $\mathrm{UVC} / \mathrm{H}_{2} \mathrm{O}_{2}$-UF $\left(120 \mathrm{mg} \mathrm{H}_{2} \mathrm{O}_{2} \mathrm{~L}^{-1}\right)$ & 10 & 51 & 52 & 0.60 \\
\hline \multirow[t]{3}{*}{ sW } & UVC-UF & 60 & 23 & 35 & 0.40 \\
\hline & $\mathrm{UVC} / \mathrm{TiO}_{2}$-UF $\left(1.0 \mathrm{~g} \mathrm{TiO}_{2} \mathrm{~L}^{-1}\right)$ & 15 & 52 & 55 & 0.68 \\
\hline & $\mathrm{UVC} / \mathrm{H}_{2} \mathrm{O}_{2}$-UF $\left(120 \mathrm{mg} \mathrm{H}_{2} \mathrm{O}_{2} \mathrm{~L}^{-1}\right)$ & 10 & 64 & 65 & 0.62 \\
\hline
\end{tabular}

\footnotetext{
${ }^{\text {a }}$ Defined as the time required to reduce the initial OTC concentration to below the detection limit.

${ }^{b}$ Defined as the ratio between the permeate flux after $5 \mathrm{~h}$ of experiment and the initial one.

${ }^{c}$ Defined as the overall efficiency of DOC removal in the feed $\left[\left(F_{0}-F_{5}\right) / F_{0} \times 100 \%\right]$. $F_{0}$ represents the feed initial DOC concentration and $F_{5}$ is the DOC concentration in the feed after $5 \mathrm{~h}$.

${ }^{\mathrm{d}}$ Defined as the total efficiency of DOC removal, regarding the feed and permeate composition $\left[\left(F_{0}-P_{5}\right) / F_{0} \times 100 \%\right]$. $F_{O}$ represents the feed initial DOC concentration and $P_{5}$ is the DOC concentration on the permeate after a reaction period of $5 \mathrm{~h}$.
} 
mask the photosensitive surface of the photocatalyst particles, hindering the light dissemination [33]. Therefore, $1.0 \mathrm{~g} \mathrm{~L}^{-1}$ of $\mathrm{TiO}_{2}$ proved to be the most viable dosage within the investigated photocatalysts loadings. It is also worth noting the difference between $R_{\text {feed }}$ and $R_{\text {total }}$ values, which can be attributed to the rejection of larger molecular weight organic pollutants by the membrane. These data clearly show that membrane separation played an important role on the overall treatment efficiency. Furthermore, the system exhibited an effective rejection of photocatalyst particles from the treated water, allowing its recovery. The permeate had a turbidity $<1.0$ NTU, value 4100 times lower than the feed turbidity of one containing $\mathrm{TiO}_{2}$ particles.

\subsection{OTC removal from Secondary Effluent during UVC photolysis and $\mathrm{UVC} / \mathrm{H}_{2} \mathrm{O}_{2}$ processes coupled with $\mathrm{UF}$}

The second stage of the research was focused on the OTC removal ( $5 \mathrm{mg} \mathrm{L}^{-1}$ ) from SE using the hybrid UVC photolysis-UF and UVC/ $\mathrm{H}_{2} \mathrm{O}_{2}$-UF systems, varying the $\mathrm{H}_{2} \mathrm{O}_{2}$ concentrations from 30 to $120 \mathrm{mg} \mathrm{L}^{-1}$. The OTC oxidation by $\mathrm{H}_{2} \mathrm{O}_{2}$ (in the absence of light) showed to be feasible. However, this reaction is slow and, at the tested conditions $\left(\mathrm{pH}=7.4\right.$ and $\left.20^{\circ} \mathrm{C}\right)$, only a maximum of $12 \%$ of OTC removal was obtained after $5 \mathrm{~h}$ of reaction (data not shown).

When using the UVC-UF system, the permeate flux was significantly lower than the PWF due to the poor degradation of large organic molecules responsible for the membrane fouling (Fig. S3, Table 1). It was observed a systematic decrease of $34 \%$ of the initial permeate flux, achieving a final deterioration of about $60 \%$ (during the $5 \mathrm{~h}$ of the reaction). The addition of an oxidant to the system enhanced the permeate flux values within the oxidant concentrations tested. When using the highest $\mathrm{H}_{2} \mathrm{O}_{2}$ amount, the permeate flux reached a similar value to the one optimized in the $\mathrm{UVC} / \mathrm{TiO}_{2}$ - $\mathrm{UF}$ system $(60 \%$ of the initial value), at the end of process.

The UVC-UF process was found to be efficient for the OTC degradation, achieving a total removal in $5 \mathrm{~h}$, but not for the complete solution mineralization $\left(R_{\text {feed }}=22 \%\right.$ and $\left.R_{\text {total }}=30 \%\right)$. A change in colour from pale yellow to pale orange was observed, probably due to the poor mineralization of the parent compounds and to the formation of by-products that were not photodegraded. A 2.25-fold decrease on the OTC degradation time occurred with the addition of $30 \mathrm{mg} \mathrm{L}^{-1}$ of $\mathrm{H}_{2} \mathrm{O}_{2}$ when compared with the UVC-UF system. In fact, an improvement on the OTC removal rates was verified with increasing $\mathrm{H}_{2} \mathrm{O}_{2}$ amounts (Fig. 2a), but even with the lowest oxidant concentration tested, $30 \mathrm{mg} \mathrm{L}^{-1}$, the OTC was no longer detected on the feed after $30 \mathrm{~min}$ of reaction. López-Peñalver et al. [40] reported $97 \%$ of tetracyclines (TC) removal from wastewater using an $\mathrm{UVC} / \mathrm{H}_{2} \mathrm{O}_{2}$ process (without a filtration system) only after $60 \mathrm{~min}$. The slower antibiotic degradation described can be due to the lower concentration of oxidant used $\left(10 \mathrm{mg} \mathrm{H}_{2} \mathrm{O}_{2} \mathrm{~L}^{-1}\right.$ ) and to the absence of the membrane separation process.

In addition, in this study, the mineralization efficiency was also significantly enhanced with $\mathrm{H}_{2} \mathrm{O}_{2}$ addition. Within $5 \mathrm{~h}$ of reaction, DOC removals in feed reached 35,47 and $51 \%$ for $\mathrm{H}_{2} \mathrm{O}_{2}$ concentrations of 30,60 and $120 \mathrm{mg} \mathrm{L}^{-1}$, respectively (Table 1 ). The homolytic cleavage of $\mathrm{H}_{2} \mathrm{O}_{2}$ molecules by UVC irradiation leads to an enhancement of the OTC oxidation by the $\mathrm{HO}^{*}$ radicals produced. In fact, at the end of the treatment process, transparent treated solutions were observed. The differences observed between the DOC removals on the feed and the permeate show that the membrane had an important role when using the systems UVC-UF and UVC/ $\mathrm{H}_{2} \mathrm{O}_{2}$-UF with $30 \mathrm{mg} \mathrm{L}^{-1}$ of $\mathrm{H}_{2} \mathrm{O}_{2}$, as presented in Fig. $2 \mathbf{b}$. As it was above mentioned, without the addition of oxidant or with a low oxidant dosage, there is a low mineralization of the solution. As a result, larger molecules are rejected by the membrane, remaining in the feed solution. On the other hand, a slightly lower contribution of the membrane separation to the overall treatment efficiency was observed when using a $\mathrm{H}_{2} \mathrm{O}_{2}$ concentration of $60 \mathrm{mg} \mathrm{L}^{-1}$ and, with the highest oxidant dosage studied $\left(120 \mathrm{mg} \mathrm{H}_{2} \mathrm{O}_{2} \mathrm{~L}^{-1}\right)$, the

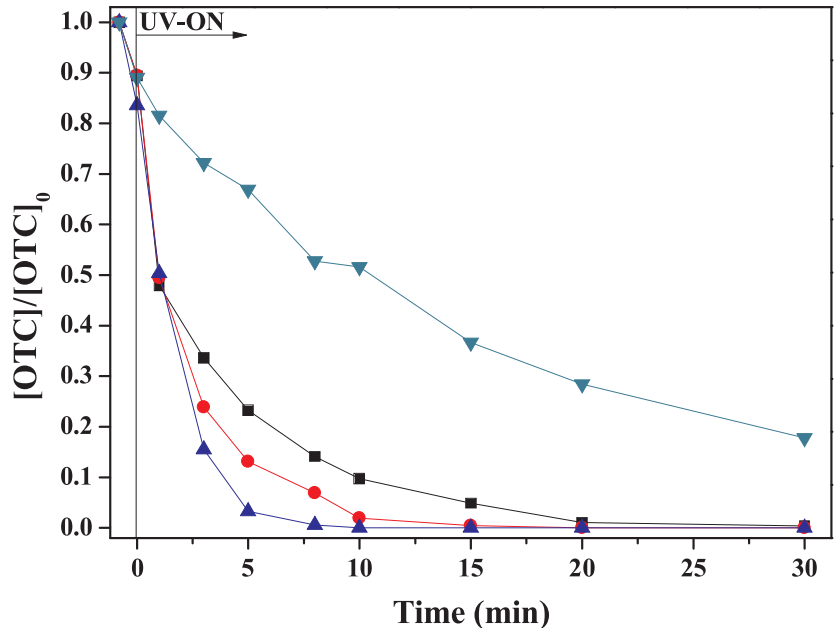

(a)

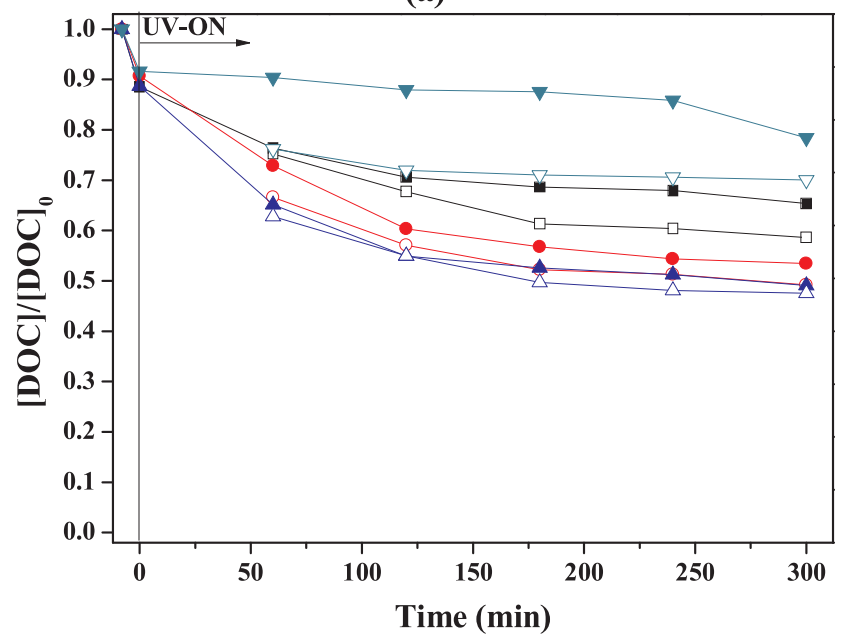

(b)

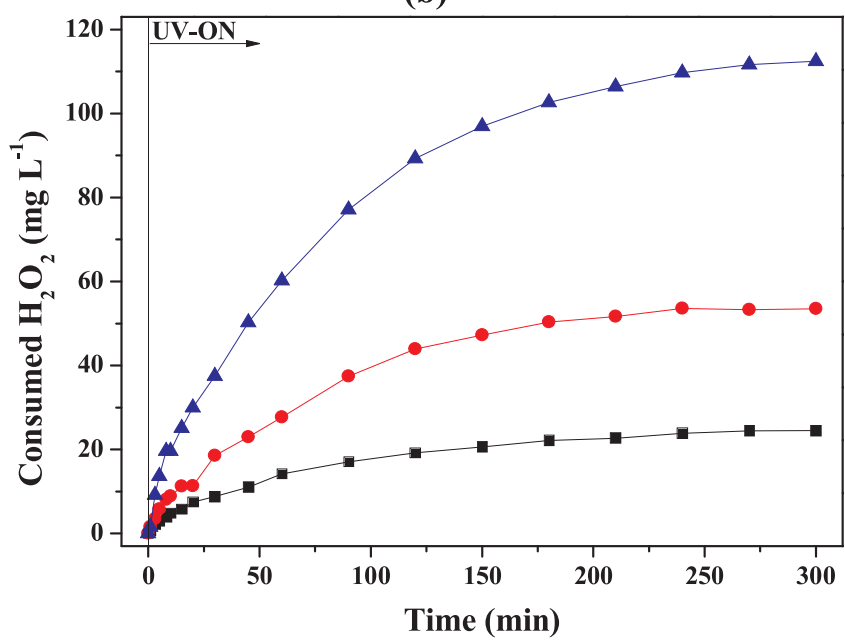

(c)

Fig. 2. Influence of $\mathrm{H}_{2} \mathrm{O}_{2}$ concentration on OTC degradation from SE by UVC/ $\mathrm{H}_{2} \mathrm{O}_{2}$-UF system in terms of (a) OTC removal on feed, (b) DOC removal on feed (closed symbols) and permeate (open symbols) and (c) $\mathrm{H}_{2} \mathrm{O}_{2}$ consumption as a

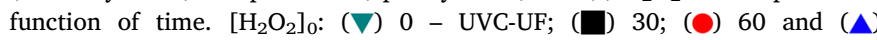
$120 \mathrm{mg} \mathrm{L}^{-1}$. Conditions: $\quad[\mathrm{OTC}]_{0}=5.0 \mathrm{mg} \mathrm{L}^{-1} ; \quad \mathrm{pH}=7.4, \quad \mathrm{~T}=20^{\circ} \mathrm{C}$; $\mathrm{CFV}=6 \mathrm{~m} \mathrm{~s}^{-1} ; \mathrm{TMP}=0.1 \mathrm{MPa}$.

feed and total DOC removals are practically the same. The absence of differences between DOC removals in the permeate and in the feed samples confirms the more efficient degradation of the organic 
pollutants into low molecular weight compounds capable of passing through the membrane in the presence of higher dosages of $\mathrm{H}_{2} \mathrm{O}_{2}$.

It has to be noted that the hydrogen peroxide molecules are not rejected by the UF membrane, passing freely to the permeate. This way, the same amount of oxidant was detected in both feed and permeate samples, at the same reaction times. The $\mathrm{H}_{2} \mathrm{O}_{2}$ consumption was higher when a higher initial $\mathrm{H}_{2} \mathrm{O}_{2}$ dose was used (Fig. 2c). However, the increase of the oxidant concentration from 60 to $120 \mathrm{mg} \mathrm{L}^{-1}$ did not lead to a proportional increase in the OTC degradation, probably due to the $\mathrm{H}_{2} \mathrm{O}_{2}$ consumption in parasitic reactions. The remnant concentrations at the end of all the reactions were lower than $2.5 \mathrm{mg} \mathrm{H}_{2} \mathrm{O}_{2} \mathrm{~L}^{-1}$.

Therefore, the $\mathrm{H}_{2} \mathrm{O}_{2}$ concentration of $120 \mathrm{mg} \mathrm{L}^{-1}$ was found to be the most beneficial one, in terms of membrane performance and pollutants degradation, among all the examined doses. The system proved to be a promising method for CECs removal present in municipal wastewaters. However, taking into account that hydrogen peroxide is a strong oxidant and its presence in treated wastewaters is not desired, the residual concentration of $\mathrm{H}_{2} \mathrm{O}_{2}$ should be carefully monitored.

\subsection{OTC removal from Miedwie Lake water using different hybrid AOP-UF processes}

In the third stage of assays, the removal of $5 \mathrm{mg} \mathrm{L}^{-1}$ of OTC from a surface water (SW) from Miedwie Lake was evaluated using different hybrid AOP-UF processes (UVC/ $\mathrm{TiO}_{2}$-UF and UVC/ $\mathrm{H}_{2} \mathrm{O}_{2}$-UF) or UVCUF system. $1.0 \mathrm{~g} \mathrm{TiO}_{2} \mathrm{~L}^{-1}$ and $120 \mathrm{mg} \mathrm{H}_{2} \mathrm{O}_{2} \mathrm{~L}^{-1}$ were applied in the $\mathrm{UVC} / \mathrm{TiO}_{2}$-UF and UVC/ $\mathrm{H}_{2} \mathrm{O}_{2}$-UF systems, respectively, corresponding to the optimum values found when using the $\mathrm{SE}$ as reaction matrix. As in the previous studies, despite achieving a complete OTC degradation in $60 \mathrm{~min}$, a low mineralization (DOC removal of 35\%, even after $5 \mathrm{~h}$ ) was verified when using the UVC-UF process. Table 1 shows that the addition of the oxidant or photocatalyst proved to enhance significantly the efficiency of the systems. During the UVC/TiO ${ }_{2}$-UF operation, the OTC was no longer detected after $15 \mathrm{~min}$ of reaction and the total DOC concentration was reduced in $55 \%$ at the end of process $(5 \mathrm{~h})$. When using the UVC/ $\mathrm{H}_{2} \mathrm{O}_{2}$-UF system, the OTC total oxidation (below the detection limit) was achieved in $10 \mathrm{~min}$, attaining a DOC removal of $65 \%$ in $5 \mathrm{~h}$. The effluent matrix proved to affect both the OTC removal and mineralization. The hybrid system $\mathrm{UVC} / \mathrm{H}_{2} \mathrm{O}_{2}$-UF showed to attain the higher DOC removals and the faster OTC removal. This system also showed a higher efficiency on the degradation of large molecular weight organic pollutants, evidenced by the negligible difference between DOC removals in the feed and permeate. All the experiments with the SW as reaction matrix achieved higher mineralization values and OTC degradation rates than with SE. For example, when using SE as feed matrix for the UVC/ $\mathrm{H}_{2} \mathrm{O}_{2}$-UF $\left(120 \mathrm{mg} \mathrm{H}_{2} \mathrm{O}_{2} \mathrm{~L}^{-1}\right)$ system, a DOC removal of about $52 \%$ was attained; when using the lake water as feed, a $R_{\text {total }}$ of $65 \%$ was achieved. This fact can be explained by the higher COD and inorganic salts concentration in the SE (Table S1), especially alkali and alkaline earth metals ions and inorganic carbon ( $\mathrm{HO}^{\circ}$ scavengers [41,42]). Yuan et al. [43] reported also the negative effect of a wastewater effluent matrix on OTC degradation using a $\mathrm{UVC} / \mathrm{H}_{2} \mathrm{O}_{2}$ system, when compared with other water matrices (ultrapure water, surface water and drinking water).

The obtained results revealed that, despite the better results achieved with the UVC/ $\mathrm{H}_{2} \mathrm{O}_{2}$-UF system, both $\mathrm{UVC} / \mathrm{TiO}_{2}$-UF and UVC/ $\mathrm{H}_{2} \mathrm{O}_{2}$-UF hybrid processes are promising methods for the tertiary treatment of WWTP effluents and for the removal of CECs from surface waters.

\section{Conclusions}

The performance of three different hybrid systems coupling i) ultrafiltration (UF) and advanced oxidation processes (UVC $/ \mathrm{H}_{2} \mathrm{O}_{2}$ and $\mathrm{UVC} / \mathrm{TiO}_{2}$ photocatalysis) or ii) UF and UVC photolysis, was compared for the treatment of a secondary effluent and a surface water spiked with a model antibiotic, oxytetracycline (OTC $-\mathrm{C}_{22} \mathrm{H}_{24} \mathrm{~N}_{2} \mathrm{O}_{9}$ ). All the studied systems proved to attain the complete degradation of $\mathrm{C}_{22} \mathrm{H}_{24} \mathrm{~N}_{2} \mathrm{O}_{9}$. The permeate flux proved to be significantly influenced by the photocatalyst loading and oxidant concentration. The lowest permeate flux was observed with the UVC-UF system, due to its low mineralization efficiency. When using the $\mathrm{UVC} / \mathrm{TiO}_{2}$-UF system, the adsorption of the organic contaminants on the $\mathrm{TiO}_{2}$ particles contributed significantly to the overall treatment efficiency and the membrane showed to have a significant role on the pollutants and photocatalyst particles separation from the treated water. A photocatalyst concentration of $1.0 \mathrm{~g} \mathrm{~L}^{-1}$ was observed to originate the best performance. When using the UVC/ $\mathrm{H}_{2} \mathrm{O}_{2}$-UF system, with the highest $\mathrm{H}_{2} \mathrm{O}_{2}$ concentration (120 mg He $\mathrm{H}_{2} \mathrm{~L}^{-1}$ ), a higher degradation of the organic pollutants was achieved due to the generation of larger amounts of hydroxyl radicals, making the role of the membrane marginal. The presence of higher COD and inorganic salts dosages in the SE resulted in lower mineralizations and slower OTC degradations than in SW, for all the hybrid systems studied.

The hybrid system coupling UVC/ $\mathrm{H}_{2} \mathrm{O}_{2}$ process $\left(120 \mathrm{mg} \mathrm{H}_{2} \mathrm{O}_{2} \mathrm{~L}^{-1}\right)$ with a UF ceramic membrane (UVC/ $\mathrm{H}_{2} \mathrm{O}_{2}$-UF system) showed the best results regarding the permeate flux and pollutants degradation, proving to be an effective technology for the removal of pharmaceuticals from waste and surface waters. Furthermore, the process seems to be attractive also in terms of retentate disposal, since the concentrate does not contain photocatalyst particles.

\section{Acknowledgements}

This work was partially financially supported by Project POCI-010145-FEDER-006984 - Associate Laboratory LSRE-LCM funded by FEDER through COMPETE2020 - Programa Operacional Competitividade e Internacionalização (POCI) - and by national funds through FCT - Fundação para a Ciência e a Tecnologia. V.J.P. Vilar acknowledges the FCT Investigator 2013 Programme (IF/00273/2013). J.C.A. Espíndola acknowledges CNPq (Brazil) for his scholarship (205781/2014-4). R.O. Cristóvão thanks FCT for her Post-doc Scholarship (SFRH/BPD/101456/2014).

\section{Appendix A. Supplementary data}

Supplementary data associated with this article can be found, in the online version, at https://doi.org/10.1016/j.cattod.2018.12.040.

\section{References}

[1] K. Kümmerer, Antibiotics in the aquatic environment - a review - part I, Chemosphere 75 (2009) 417-434.

[2] P. Verlicchi, A. Galletti, M. Petrovic, D. Barceló, Hospital effluents as a source of emerging pollutants: an overview of micropollutants and sustainable treatment options, J. Hydrol. (Amst.) 389 (2010) 416-428.

[3] I. Michael, L. Rizzo, C.S. McArdell, C.M. Manaia, C. Merlin, T. Schwartz, C. Dagot, D. Fatta-Kassinos, Urban wastewater treatment plants as hotspots for the release of antibiotics in the environment: a review, Water Res. 47 (2013) 957-995.

[4] X. Liu, S. Lu, W. Guo, B. Xi, W. Wang, Antibiotics in the aquatic environments: a review of lakes, China, Sci. Total Environ. 627 (2018) 1195-1208.

[5] A. Puckowski, K. Mioduszewska, P. Łukaszewicz, M. Borecka, M. Caban, J. Maszkowska, P. Stepnowski, Bioaccumulation and analytics of pharmaceutical residues in the environment: a review, J. Pharm. Biomed. Anal. 127 (2016) $232-255$.

[6] K. Kümmerer, The presence of pharmaceuticals in the environment due to human use - present knowledge and future challenges, J. Environ. Manage. 90 (2009) 2354-2366.

[7] J.H.O.S. Pereira, A.C. Reis, D. Queirós, O.C. Nunes, M.T. Borges, V.J.P. Vilar, R.A.R. Boaventura, Insights into solar $\mathrm{TiO}_{2}$-assisted photocatalytic oxidation of two antibiotics employed in aquatic animal production, oxolinic acid and oxytetracycline, Sci. Total Environ. 463-464 (2013) 274-283.

[8] S. Malato, P. Fernández-Ibáñez, M.I. Maldonado, J. Blanco, W. Gernjak, Decontamination and disinfection of water by solar photocatalysis: recent overview and trends, Catal. Today 147 (2009) 1-59.

[9] V.C. Sarasidis, K.V. Plakas, A.J. Karabelas, Novel water-purification hybrid processes involving in-situ regenerated activated carbon, membrane separation and advanced oxidation, Chem. Eng. J. 328 (2017) 1153-1163. 
[10] S. Mozia, D. Darowna, K. Szymański, S. Grondzewska, K. Borchert, R. Wróbel, A.W. Morawski, Performance of two photocatalytic membrane reactors for treatment of primary and secondary effluents, Catal. Today 236 (2014) 135-145.

[11] S. Mozia, Photocatalytic membrane reactors (PMRs) in water and wastewater treatment. A review, Sep. Purif. Technol. 73 (2010) 71-91.

[12] D. Darowna, R. Wróbel, A.W. Morawski, S. Mozia, The influence of feed composition on fouling and stability of a polyethersulfone ultrafiltration membrane in a photocatalytic membrane reactor, Chem. Eng. J. 310 (2017) 360-367.

[13] R. Molinari, M. Mungari, E. Drioli, A. Di Paola, V. Loddo, L. Palmisano, M. Schiavello, Study on a photocatalytic membrane reactor for water purification, Catal. Today 55 (2000) 71-78.

[14] S.S. Chin, K. Chiang, A.G. Fane, The stability of polymeric membranes in a TiO2 photocatalysis process, J. Membr. Sci. 275 (2006) 202-211.

[15] S.O. Ganiyu, E.D. van Hullebusch, M. Cretin, G. Esposito, M.A. Oturan, Coupling of membrane filtration and advanced oxidation processes for removal of pharmaceutical residues: a critical review, Sep. Purif. Technol. 156 (2015) 891-914.

[16] Y.H. Wang, X.Q. Liu, G.Y. Meng, Preparation of asymmetric pure titania ceramic membranes with dual functions, Mater. Sci. Eng. A 445-446 (2007) 611-619.

[17] M. Kosmulski, P. Prochniak, J.B. Rosenholm, Electroacoustic study of titania at high concentrations of 1-2, 2-1 and 2-2 electrolytes, Colloids Surf. A Physicochem. Eng. Asp. 345 (2009) 106-111.

[18] S. Kim, K.H. Chu, Y.A.J. Al-Hamadani, C.M. Park, M. Jang, D.-H. Kim, M. Yu, J. Heo, Y. Yoon, Removal of contaminants of emerging concern by membranes in water and wastewater: a review, Chem. Eng. J. 335 (2018) 896-914.

[19] Y. Yoon, P. Westerhoff, S.A. Snyder, E.C. Wert, Nanofiltration and ultrafiltration of endocrine disrupting compounds, pharmaceuticals and personal care products, J. Membr. Sci. 270 (2006) 88-100.

[20] V.C. Sarasidis, K.V. Plakas, S.I. Patsios, A.J. Karabelas, Investigation of diclofenac degradation in a continuous photo-catalytic membrane reactor. Influence of operating parameters, Chem. Eng. J. 239 (2014) 299-311.

[21] Y. Liu, X. He, Y. Fu, D.D. Dionysiou, Degradation kinetics and mechanism of oxytetracycline by hydroxyl radical-based advanced oxidation processes, Chem. Eng. J. 284 (2016) 1317-1327.

[22] N. Kemper, Veterinary antibiotics in the aquatic and terrestrial environment, Ecol. Indic. 8 (2008) 1-13.

[23] A.K. Sarmah, M.T. Meyer, A.B.A. Boxall, A global perspective on the use, sales, exposure pathways, occurrence, fate and effects of veterinary antibiotics (VAs) in the environment, Chemosphere 65 (2006) 725-759.

[24] G. Rigos, I. Nengas, M. Alexis, Oxytetracycline (OTC) uptake following bath treatment in gilthead sea bream (Sparus aurata), Aquaculture 261 (2006) 1151-1155.

[25] D. Li, M. Yang, J. Hu, L. Ren, Y. Zhang, K. Li, Determination and fate of oxytetracycline and related compounds in oxytetracycline production wastewater and the receiving river, Environ. Toxicol. Chem. 27 (2008) 80-86.

[26] D.W. Kolpin, E.T. Furlong, M.T. Meyer, E.M. Thurman, S.D. Zaugg, L.B. Barber, H.T. Buxton, Pharmaceuticals, hormones, and other organic wastewater contaminants in U.S. streams, 1999-2000: a national reconnaissance, Environ. Sci. Technol. 36 (2002) 1202-1211.

[27] Y. Liu, X. He, X. Duan, Y. Fu, D.D. Dionysiou, Photochemical degradation of oxytetracycline: influence of $\mathrm{pH}$ and role of carbonate radical, Chem. Eng. J. 276
(2015) 113-121.

[28] J.H.O.S. Pereira, D.B. Queirós, A.C. Reis, O.C. Nunes, M.T. Borges, R.A.R. Boaventura, V.J.P. Vilar, Process enhancement at near neutral $\mathrm{pH}$ of a homogeneous photo-Fenton reaction using ferricarboxylate complexes: application to oxytetracycline degradation, Chem. Eng. J. 253 (2014) 217-228.

[29] S. Belkacem, S. Bouafia, M. Chabani, Study of oxytetracycline degradation by means of anodic oxidation process using platinized titanium (Ti/Pt) anode and modeling by artificial neural networks, Process. Saf. Environ. Prot. 111 (2017) $170-179$

[30] Y. Liu, X. He, Y. Fu, D.D. Dionysiou, Kinetics and mechanism investigation on the destruction of oxytetracycline by UV-254 nm activation of persulfate, J. Hazard. Mater. 305 (2016) 229-239.

[31] J.H.O.S. Pereira, V.J.P. Vilar, M.T. Borges, O. González, S. Esplugas, R.A.R. Boaventura, Photocatalytic degradation of oxytetracycline using $\mathrm{TiO}_{2}$ under natural and simulated solar radiation, Sol. Energy 85 (2011) 2732-2740.

[32] S.-z. Li, X.-y. Li, D.-z. Wang, Membrane (RO-UF) filtration for antibiotic wastewater treatment and recovery of antibiotics, Sep. Purif. Technol. 34 (2004) 109-114.

[33] K. Szymański, A.W. Morawski, S. Mozia, Humic acids removal in a photocatalytic membrane reactor with a ceramic UF membrane, Chem. Eng. J. 305 (2016) 19-27.

[34] S. Mozia, K. Szymański, B. Michalkiewicz, B. Tryba, M. Toyoda, A.W. Morawski, Effect of process parameters on fouling and stability of $\mathrm{MF} / \mathrm{UF} \mathrm{TiO}_{2}$ membranes in a photocatalytic membrane reactor, Sep. Purif. Technol. 142 (2015) 137-148.

[35] H.J. Kuhn, S.E. Braslavsky, R. Schmidt, Chemical actinometry (IUPAC technical report), Pure Appl. Chem. (2004) 2105

[36] S. Mozia, M. Janus, P. Brożek, S. Bering, K. Tarnowski, J. Mazur, A. Morawski, A system coupling hybrid biological method with $\mathrm{UV} / \mathrm{O}_{3}$ oxidation and membrane separation for treatment and reuse of industrial laundry wastewater, Environ. Sci. Pollut. Res. Int. (2016).

[37] R.F.P. Nogueira, M.C. Oliveira, W.C. Paterlini, Simple and fast spectrophotometric determination of $\mathrm{H}_{2} \mathrm{O}_{2}$ in photo-Fenton reactions using metavanadate, Talanta 66 (2005) 86-91.

[38] W. Liu, S.A. Andrews, M.I. Stefan, J.R. Bolton, Optimal methods for quenching H2O2 residuals prior to UFC testing, Water Res. 37 (2003) 3697-3703.

[39] K. Szymański, A.W. Morawski, S. Mozia, Surface water treatment in hybrid systems coupling advanced oxidation processes and ultrafiltration using ceramic membrane, Desalin. Water Treat. 64 (2017) 302-306.

[40] J.J. López-Peñalver, M. Sánchez-Polo, C.V. Gómez-Pacheco, J. Rivera-Utrilla, Photodegradation of tetracyclines in aqueous solution by using $\mathrm{UV}$ and $\mathrm{UV} / \mathrm{H}_{2} \mathrm{O}_{2}$ oxidation processes, J. Chem. Technol. Biotechnol. 85 (2010) 1325-1333.

[41] C. Oliveira, D.L.D. Lima, C.P. Silva, V. Calisto, M. Otero, V.I. Esteves, Photodegradation of sulfamethoxazole in environmental samples: the role of $\mathrm{pH}$, organic matter and salinity, Sci. Total Environ. 648 (2019) 1403-1410.

[42] I.K. Konstantinou, T.A. Albanis, $\mathrm{TiO}_{2}$-assisted photocatalytic degradation of azo dyes in aqueous solution: kinetic and mechanistic investigations: a review, Appl Catal. B 49 (2004) 1-14.

[43] F. Yuan, C. Hu, X. Hu, D. Wei, Y. Chen, J. Qu, Photodegradation and toxicity changes of antibiotics in UV and UV/ $\mathrm{H}_{2} \mathrm{O}_{2}$ process, J. Hazard. Mater. 185 (2011) 1256-1263. 